\title{
Which Invasive Electrode to Implant in Humans for Prosthetic use?
}

\author{
Philip Kennedy* \\ Department of Health and Human Services, USA
}

*Corresponding author: Philip Kennedy, Department of Health and Human Services, USA.

Received Date: February 04, 2020

Published Date: February 11, 2020

\section{Opinion}

It has long been maintained that tine type electrodes are adequate for long-term prosthetic command signals. Even Elon Musk has developed an electrode that is claimed to record 3072 single units [1]. He further claims it can be used for long-term prosthetic devices. The tine type Utah array (Blackrockmicro Inc.) has been championed as the savior of long-term prosthetic control. However, even the researchers admit that its lifetime is limited because it loses $85 \%$ of single units within three years [2]. It suffers the fate of all foreign bodies, namely, scarring at the electrode tip. This will obviously occur with all metal and tine type electrodes that pierce the cortex. So move over Blackrock, move over Elon, there is another way to do it.

The other way has been in development since 1986. It turns the approach on its head by growing the brain neuropil into the electrode tip. A tiny glass cone is inserted into the cortex with a magic sauce inside, namely, nerve growth factors. These factors induce growth into and through the tip. In addition, the recording wires are 2 mil 99.999\% gold with Teflon insulation, and these are glued inside the glass cone. Moreover, they are coiled for strain relief so there is no strain on the tip. All components are biocompatible. Here is an illustration (Figure 1).

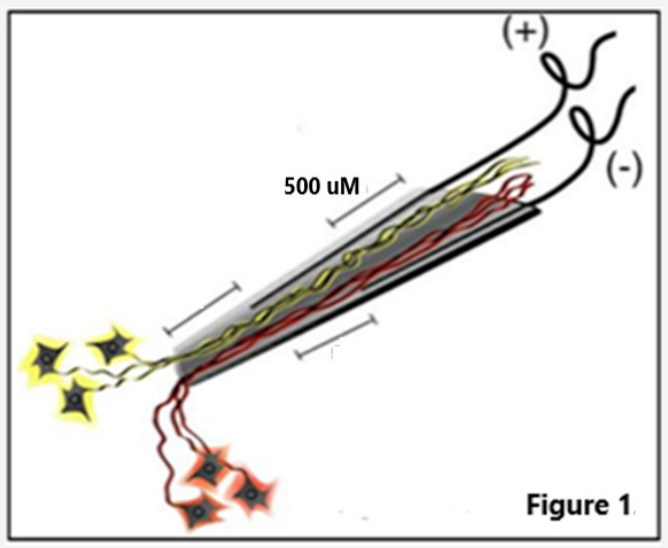

Figure 1:

Of course, the criticism is that it destroys cortex into which it is inserted. But so, what? This cortex, though still viable, is useless to someone who is paralyzed and mute. Another criticism is that it must cause lots of scarring and the signals will be lost. First, no data has ever shown scarring, whether in rats [3], monkeys [3] or humans [4]. The latest human subject revealed no postmortem scarring after 13 years of implantation [4]. Moreover, the histology demonstrated myelinated neurafilaments adjacent to the recording wires [4].

So the criticism is that the recorded signal have changed and died away just like the tine type electrodes. Not so. Single units are stable even as long as 10 years in the above subject [4] who was too ill to continue recording after 10 years. Conditioning studies at the 
end of the decade demonstrated functional single units [5,6]. Other long-term humans had functional signals at four years [7]. These studies cement its position as the long-term recording electrode.

So why is it not being used more often? It is FDA approved for use in humans (IDE 960032). I imagine it is too difficult to implant. Some have tried and failed. It requires a trained and skilled neurosurgeon for human implantation. The main reason, perhaps, is because it is not sexy enough, it looks awful, it takes a few hours to make by hand, so it is out of fashion. Millions of dollars has been spent on the tine type electrodes and no one wants to see an investment rendered useless. Indeed, the tine types have been proven extremely useful in shorter term studies (months and years) [8]. But data is data. And the data is now irrefutable for longterm studies [4-6]

\section{Conclusion}

It should be used in human prosthetic work where long-term recordings are required.

\section{Acknowledgment}

None.

\section{Conflict of Interest}

No conflict of interest.

\section{References}

1. Musk E (2019) An integrated brain-machine interface platform with thousands of channels. J Med Internet Res 21(10): e16194.

2. Downey JE, Schwed N, Chase SM, Schwartz AB, Collinger JL (2018) Intracortical recording stability in human brain-computer interface users. J Neural Eng 15(4): 046016.

3. Kennedy PR, Mirra S, Bakay RAE (1992) The Cone Electrode: Ultrastructural Studies Following Long-Term Recording. Neurosci Lett 142(1): 89-94.

4. Gearin M, Kennedy PR (2020) Histological confirmation of myelinated neural filaments within the tip of the Neurotrophic Electrode after a decade of neural recordings.

5. Kennedy PR, Gambrell C, Ehirim P, Cervantes A (2017) Advances in the development of a speech prosthesis. Book chapter in Brain-Machine Interfaces: Uses and Developments.

6. Kennedy PR, Andreasen DS, Bartels J, Wright EJ, Seibert S, et al. (2018) Validation of Neurotrophic Electrode long term recordings in Human Cortex. Handbook of Biomedical Engineering.

7. Kennedy PR, Bakay RAE, Adams K, Goldthwaite J (2000) Direct control of a computer from the human central nervous system. IEEE Trans. Rehab Eng 8(2): 198-202.

8. Hochberg LR, Bacher D, Jarosiewicz B, Masse NY, Simeral JD, et al. (2012) Reach and grasp by people with tetraplegia using a neurally controlled robotic arm. Nature 485(7398): 372-375. 